\title{
Field and allozyme studies investigating optimal mating success in two sympatric spring-ephemeral plants, Trillium erectum and T. grandiflorum
}

\author{
REBECCA E. IRWIN \\ Biology Department, University of Vermont, Burlington, Vermont 05405-0086 U.S.A.
}

\begin{abstract}
A combination of field experiments and allozyme studies was used to test whether two springephemeral plants growing in eastern North America, Trillium erectum and T. grandiflorum (Liliaceae), exhibited an optimal outcrossing distance for fruit and seed production. Furthermore, the spatial genetic structure of the Trillium populations was examined in light of the outcrossing results. In field experiments, recipient plants were pollinated with either self pollen or with pollen from donors growing $1 \mathrm{~m}, 10 \mathrm{~m}, 100 \mathrm{~m}$, and $1500 \mathrm{~m}$ away. These distances represented crosses between individuals growing within the same population $(1 \mathrm{~m}, 10 \mathrm{~m}$, and $100 \mathrm{~m}$ crosses) and between individuals growing in different populations $(1500 \mathrm{~m}$ crosses). Self-pollinated $T$. erectum and T. grandiflorum produced $71 \%$ and $89 \%$ fewer seeds, respectively, than all other outcrossing treatments. However, there were no significant differences among outcrossing treatments for fruit or seed production. As neither T. erectum nor T. grandiflorum exhibited an optimal outcrossing distance for fruit or seed production, it was predicted that populations of the two would not demonstrate strong spatial genetic structure or isolation by distance. The allozyme results only partially supported the patterns revealed in the outcrossing treatments. Populations of T. erectum and T. grandiflorum showed moderate spatial genetic differentiation based on F-statistics, and only $T$. grandiflorum exhibited significant isolation by distance based on spatial autocorrelation analyses. The lack of optimal outcrossing distances and the patterns of allozyme variation in T. erectum and T. grandiflorum populations may be attributed to a number of factors, including active seed dispersal by ants, rare long-distance gene-flow events, post-pollination and post-fertilization selection, and/or the severity of inbreeding depression.
\end{abstract}

Keywords: genetic structure, inbreeding depression, optimal outcrossing, spatial autocorrelation, spring ephemerals, Trillium erectum, Trillium grandiflorum.

\section{Introduction}

Mating success depends, in part, on the quality of genes contributed by each parent (Cockerham \& Weir, 1977). Optimal matings are those that produce the highest fitness, both in number and quality of offspring (e.g. Price \& Waser, 1979; Waser \& Price, 1983; Waser, 1993). In plant populations, where gene flow via pollen and seeds is limited and leptokurtic, genetic isolation by distance may occur by genetic drift alone, even in the absence of selective gradients (Wright, 1951; Kimura \& Weiss, 1964;

Correspondence and present address: Center for Population Biology, 2320 Storer Hall, One Shields Ave., University of California, Davis, CA 95616 U.S.A. E-mail: reirwin@ucdavis.edu
Rohlf \& Schnell, 1971; Levin \& Kerster, 1974; Sokal \& Wartenberg, 1983). In these cases, neighbouring plants are likely to be kin, and the success of matings between kin may be compromised by inbreeding depression. However, if individuals are too dissimilar, outbreeding depression (Müller, 1883; Price \& Waser, 1979) may occur in matings between individuals of the same population if the population exhibits localized gene flow (e.g. Waser \& Price, 1983; Sobrevila, 1988) or between isolated populations of the same species (e.g. Vrijenhoek \& Lerman, 1982; Sobrevila, 1988). Outbreeding depression may arise from 'ecological' and/or 'genetic' mechanisms (for a review see Waser, 1993).

Given that both inbreeding and outbreeding depression may occur within the same population, there is 
likely to be an intermediate outcrossing distance at which plant matings produce the most offspring with the highest fitness. This distance, the optimal outcrossing distance (Müller, 1883; Price \& Waser, 1979; Shields, 1982; Waser \& Price, 1983; Waser, 1993), assumes a negative correlation between the genetic similarity and physical distance of mates (Price \& Waser, 1979; Waser \& Price, 1983). Several studies provide evidence for optimal outcrossing distances in a variety of plant species (e.g. Price \& Waser, 1979; Waser \& Price, 1983, 1989; Schemske \& Paulter, 1984; Sobrevila, 1988; Fischer \& Matthies, 1997; but see Redmond et al., 1989; Oostermeijer et al., 1995; Trame et al., 1995). For example, outcrossing distances of $10 \mathrm{~m}$ in the monocarpic angiosperm Ipomopsis aggregata produce more offspring with higher fitness than outcrossing distances of $1 \mathrm{~m}$ or greater than $30 \mathrm{~m}$ (Waser \& Price, 1989; Waser et al., 2000). In addition, studies have tested the assumption that optimal outcrossing is due to an inverse correlation between genetic distance and physical distance (Waser, 1987; Trame et al., 1995). However, we know little about the expression of optimal outcrossing distances across, as well as within, taxonomic groups and how that expression varies with plant reproductive biology (Waser, 1993). Furthermore, our current understanding of optimal outcrossing distance is deficient in studies involving spring-ephemeral, or vernal, plant species. The spring-ephemeral plants Trillium erectum and $T$. grandiflorum (Liliaceae), both long-lived perennial plants growing in eastern North America, provide an ideal model system to investigate the importance of optimal outcrossing distance in taxonomically related plants with different life-history strategies.

The reproductive biology and the pollen- and seeddispersal strategies of $T$. erectum and $T$. grandiflorum generate interesting predictions about the potential occurrence and length of optimal outcrossing distances. Trillium erectum has a mixed mating system $\left(t_{\mathrm{m}}=0.42\right.$; Broyles et al., 1997). The red flowers of $T$. erectum produce a decaying odour that attracts dipteran pollinators (Irwin, 2000). Furthermore, the elaiosome-bearing seeds of $T$. erectum are dispersed by ants, although the average seed-dispersal distance is unknown. In contrast, $T$. grandiflorum is predominantly outcrossing $\left(t_{\mathrm{m}}=0.76-1.0\right.$; Broyles et al., 1997; Kalisz et al., 1999). The white flowers of $T$. grandiflorum may produce nectar that attracts hymenopteran pollinators (Irwin, 2000). In general, hymenopterans exhibit higher constancy and longer pollen carryover than dipterans (i.e. Herrera, 1987; Olesen \& Warncke, 1989; see Proctor et al., 1996 for a review) so that gene flow through pollen movement may be more extensive in $T$. grandiflorum than $T$. erectum. In addition, $T$. grandiflorum seeds also bear elaiosomes, and ant-mediated seed dispersal affects the patterns of $T$. grandiflorum relatedness within populations and reduces the probability of siblings growing next to each other (Kalisz et al., 1999). Taken together, features of the reproductive biology of the two Trillium species predict stronger spatial genetic structure and isolation by distance in $T$. erectum than $T$. grandiflorum populations due to higher relative levels of selfing and limited pollen and seed movement in $T$. erectum. As such, the life history attributes of $T$. erectum could result in a short within-population optimal outcrossing distance. Conversely, as T. grandiflorum potentially disperses both its pollen and seeds over many metres, it may experience outbreeding depression only in among-population crosses.

The objective of this study was to use field and allozyme methods to test whether the two sympatric spring-ephemeral plants $T$. erectum and $T$. grandiflorum exhibit an optimal outcrossing distance. In the field study, recipient plants were hand-pollinated with donors growing at various spatial distances and subsequent fruit and seed production were measured. These distances included crosses between individuals growing within the same population and between individuals growing in different populations. In addition, the underlying spatial genetic structure of the Trillium populations was examined to test the a priori hypothesis that there is a negative correlation between genetic similarity and physical distance. In particular, the following questions were asked. (1) Do $T$. erectum and $T$. grandiflorum exhibit an optimal outcrossing distance for fruit and seed production? (2) Do T. erectum and T. grandiflorum exhibit genetic isolation by distance, and do the spatial patterns of allozyme variation explain the outcrossing results? (3) How do T. erectum and $T$. grandiflorum compare in optimal outcrossing distance and spatial genetic structure?

\section{Materials and methods}

\section{Study system}

Two sympatric populations of T. erectum and T. grandiflorum were studied, located around the Indian Brooke Reservoir in Chittenden County, Vermont, U.S.A. in mesic, deciduous woods. Each population contained $>100$ individuals of each Trillium species. Trillium erectum and $T$. grandiflorum bloom from late-April to early June in the study populations. Mature plants of both species usually consist of one stem emerging from a tuber-like rhizome. Each stem bears a whorl of three leaves and a single terminal flower with three petals. The flowers of both species have six anthers and one tripartite stigma. Pollen receipt limits fruit and/or seed production in both species in the populations studied 
here (Irwin, 2000), although pollen limitation of fruit and seed production of $T$. erectum and $T$. grandiflorum is not universal and may vary both spatially and temporally (Kalisz et al., 1999; L. Lalupine and S. Griffin, personal communication). Trillium erectum and $T$. grandiflorum flowers produce a single fruit with three locules. Because each Trillium plant usually produces only one flower in a given year, each plant produces only one fruit. Thus, 'seeds per fruit' and 'seeds per plant' in a given year are synonymous. On average, open-pollinated $T$. erectum produce (mean $\pm 1 \mathrm{SE}) 50.64 \pm 11.01 \mathrm{seeds} /$ plant and T. grandiflorum, $18.13 \pm 2.64$ seeds/plant, in the Vermont populations.

\section{Optimal outcrossing in T. erectum and $\mathrm{T}$. grandiflorum}

To examine whether there is an optimal outcrossing distance for $T$. erectum and $T$. grandiflorum, in April 1998 and April 1999, groups of five neighbouring plants (hereafter referred to as blocks) were chosen for each species based on similar plant morphologies and phenologies. Plants within each block were in close physical proximity to control for variation in resource levels among individuals within blocks. For each species, each block was at least $8 \mathrm{~m}$ from all other blocks, and blocks were distributed along a transect. All blocks of plants were in the same population. In 1998, 10 blocks of $T$. erectum and 10 blocks of $T$. grandiflorum were chosen, whilst in 1999, 18 blocks of T. erectum and 14 blocks of $T$. grandiflorum were chosen. All study flowers were emasculated before they opened, except for those in the self-pollination treatment, by gently opening the flower buds with fine-tipped tweezers and pinching off the anthers. To deter pollinating insects from entering flowers, flowers were bagged whilst at the bud stage with bags made of bridal veil. Each plant in each block was randomly assigned to one of five outcrossing treatments.

In 1998, as flowers entered the pistillate phase, they were either left unpollinated (to control for bags failing to deter pollinators) or pollinated with pollen from two donor plants growing the appropriate distance away in a randomly chosen direction. Pollen was collected from the two donor plants by rubbing a toothpick against newly dehisced anthers. The pollen was then mixed in a small plastic vial and transferred immediately to the recipient stigma. All hand-pollinated stigmas were saturated with pollen. The distances between the donor and recipient plants were: $0 \mathrm{~m}$ (self-pollinated), $1 \mathrm{~m}$ (near neighbours), $10 \mathrm{~m}$ (distant neighbours within the same population), and $100 \mathrm{~m}$ (remote neighbours within the same population and unlikely to interact via pollination). Therefore, all crosses of these distances represented crosses between donors and recipients within the same population. In the self-pollination treatment, only three anthers were emasculated from flowers to allow hand-pollination with self-pollen from the three remaining anthers.

In 1998, none of the flowers in the emasculated, unpollinated control treatment produced fruits, indicating that the bags deterred all insect pollinators from entering study flowers. Therefore, in 1999 this control treatment was removed and replaced with an outcrossing distance of $1500 \mathrm{~m}$. All recipient plants in the $1500 \mathrm{~m}$ treatment were pollinated with a donor plant growing in a different Trillium population from the recipient.

Once fruits matured (approximately six weeks after hand pollination), all fruit capsules were collected, and the mature seeds and aborted ovules in each fruit were counted.

The numbers of successfully initiated fruits among outcrossing treatments were compared using a chisquared test. Further, the number of seeds per fruit and the seed: ovule ratio (number of mature seeds produced divided by the total number of ovules per fruit) were compared among outcrossing treatments using a randomized-block ANOVA. To achieve normality and homogeneity of variances, the number of seeds per fruit was natural-log transformed and the seed : ovule ratio was arcsine-square root transformed. For both T. erectum and T. grandiflorum, flowers in 1999 produced significantly more fruits and seeds than those in $1998(P<0.05$ in all cases); therefore the data from 1998 and 1999 were analysed separately for each species. In all analyses, bagged, unpollinated control flowers were not included because they did not produce seedbearing fruits.

\section{Sample collections and electrophoresis}

In May 1999, two $150 \mathrm{~m}$ transects were established, one in each of the two Trillium populations described above (the focal Trillium population in 1998 and 1999 and the donor population for the $1500 \mathrm{~m}$ outcrossing treatment in 1999). The starting points of the two transects were approximately $1500 \mathrm{~m}$ apart, and sampling points were established every $10 \mathrm{~m}$ along each transect. Leaf samples from three flowering $T$. erectum and $T$. grandiflorum were collected within $1 \mathrm{~m}$ of each sampling point, and the geographical coordinates for each plant were noted. If no $T$. erectum and/or $T$. grandiflorum were growing within $1 \mathrm{~m}$ of the sampling point, no leaf samples were collected. In total, leaf samples from $74 T$. erectum and $94 T$. grandiflorum individuals were collected.

Leaf samples were stored at $0^{\circ} \mathrm{C}$ until enzyme extraction. A small piece of each leaf was ground in a 
Tris-HCl-PVP extraction buffer (Bournival \& Korban, 1987) and absorbed onto filter-paper (Whatman no. 3) wicks. Horizontal starch-gel electrophoresis was performed on $12 \%$ gels cooled in a refrigerator. A total of seven enzymes were scored for $T$. erectum and eight for T. grandiflorum. A morpholine-citrate buffer system (pH 6.1; Clayton \& Tretiak, 1972) was used to resolve isocitrate dehydrogenase (IDH, EC 1.1.1.41), malate dehydrogenase (MDH-1, MDH-2, MDH-3, EC 1.1.1.37), phosphoglucomutase (PGM, EC 5.4.2.2), 6-phosphogluconate dehydrogenase (6PGD-1, 6PGD-2, EC 1.1.1.44), and shikimate dehydrogenase (SKDH, EC 1.1.1.25). MDH-3 was not scored for T. erectum because it was poorly resolved.

\section{Allozyme data analyses}

$F$-statistics $\left(F_{\mathrm{IS}}, F_{\mathrm{ST}}, F_{\mathrm{IT}}\right.$; Wright, 1943,1951$)$ were calculated according to the methods of Weir \& Cockerham (1984) to characterize overall genetic subdivision. Calculations were made using the computer program FSTAT (version 1.2; Goudet, 1995). To combine information over alleles and loci and to calculate sample variances, jackknifing procedures were used. To calculate significance values of $F_{\mathrm{IS}}, F_{\mathrm{ST}}$, and $F_{\mathrm{IT}}$ over all loci, the distribution of the null hypothesis (namely $F_{\text {IS }}$ or $F_{\mathrm{ST}}$ or $F_{\mathrm{IT}}$ not $>0$ ) obtained by permutations was compared to the observed distribution for each respective $F$-statistic (Goudet, 1995).

To determine the spatial structuring of allozyme variation within and between the Trillium populations, Moran's I-values, correlation coefficients for samples separated by a given distance interval, were calculated using ROOKCASE (Sawada, 1999). Here, Moran's I examines the genetic correspondence between pairs of plants at a given distance interval relative to the total sample (Sokal \& Oden, 1978). Moran's I ranges from +1 (paired individuals have the same genotype for all enzymes sampled) to -1 . Under the null hypothesis of complete spatial randomness, the value of $I$ has an expected value of zero. Distance intervals of $20 \mathrm{~m}$ were used; both larger and smaller distance intervals did not significantly change results. Separate analyses were run on the most common allele at each locus, and the mean $I$-value was calculated across loci at each distance interval. To test the significance of $I$-values, a randomization test was used to perform 5000 permutations to estimate variances and confidence intervals.

To describe further the relationship between genetic and geographical distance for both Trillium species, Roger's (1972) genetic distance, $D$, was calculated for each pair of transect-sampling points using the computer program GENESTRUT (Constantine et al., 1994).
This index allowed the incorporation of both polymorphic and monomorphic loci. A Mantel test was used to compare the genetic and geographical distance matrices for each species (Mantel, 1967). Calculations were made using the computer program RMANTEL written by R. Dyer. The significance of the Mantel test statistic was quantified using a randomization test. The rows and columns of one matrix were randomly permuted 5000 times while holding the other constant to estimate the null distribution (Sokal \& Rohlf, 1995).

\section{Results}

\section{Optimal outcrossing in $\mathrm{T}$. erectum and $\mathrm{T}$. grandiflorum}

Neither $T$. erectum nor $T$. grandiflorum exhibited an optimal outcrossing distance for fruit and seed production over the spatial distances used in the experimental crosses. For T. erectum in 1998 and 1999, self-pollinated plants produced significantly fewer fruits (1998: $\left.\chi^{2}=9.53, P=0.023 ; 1999: \chi^{2}=16.29, P=0.0026\right)$ and seeds $\left(1998: F_{3,9}=5.89, P=0.0035 ; 1999: F_{4,17}=22.87\right.$, $P<0.0001$; Fig. 1) and had lower seed: ovule ratios (1998: $\quad F_{2,9}=7.01, \quad P=0.0014 ; \quad 1999: \quad F_{4,17}=31.63$, $P<0.0001)$ than plants in all other outcrossing treatments. However, all outcrossed plants produced successful fruits, and seed production (Fig. 1) and seed: ovule ratios did not differ significantly among the outcrossing distances. In general, fruit set and seed: ovule ratios showed similar patterns in 1998 and 1999 to the number of seeds per fruit (as in Fig. 1).

The same patterns also held for T. grandiflorum. In 1998 and 1999, self-pollinated plants produced significantly fewer fruits (1998: $\chi^{2}=22.59, P<0.0001 ; 1999$ : $\left.\chi^{2}=41.31, P<0.0001\right)$ and seeds $\left(1998: F_{3,9}=11.04\right.$, $P<0.0001 ; 1999: F_{4,13}=60.46, P<0.0001$; Fig. 2$)$ and had lower seed: ovule ratios (1998: $F_{3,9}=9.72$, $\left.P=0.0002 ; 1999: F_{4,13}=50.16, P<0.0001\right)$ than outcrossed plants. However, all outcrossed plants produced successful fruits, and seed production (Fig. 2) and seed: ovule ratios did not significantly change with increasing distance between the donor and recipient plants. In general, fruit set and seed: ovule ratios showed similar patterns in 1998 and 1999 to the number of seeds per fruit (as in Fig. 2).

For both $T$. erectum and $T$. grandiflorum, seed production and the seed: ovule ratio did not differ significantly among blocks $(P>0.05)$. In addition, the bagged, unpollinated control flowers in 1998 did not produce seed-bearing fruits, indicating that bags made of bridal veil deterred all insect pollinators from entering study flowers. 

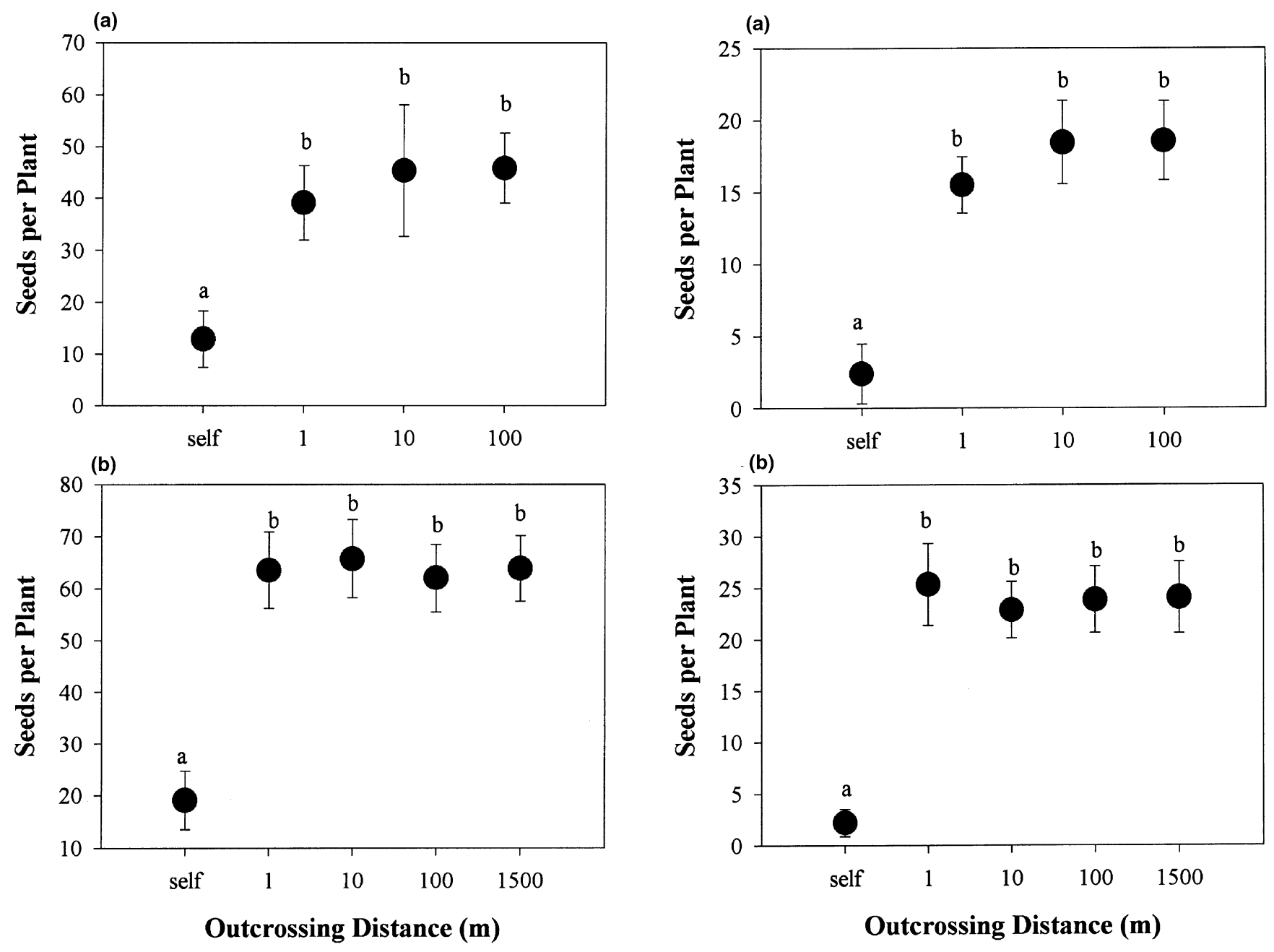

Fig. 1 Trillium erectum: number of seeds per fruit (mean \pm $1 \mathrm{SE}$ ) from crosses with donors at (a) four distance classes in 1998 and (b) five distance classes in 1999. Different lower-case letters indicate significant differences among pollination treatments at $P<0.05$ using a Tukey's HSD test.

\section{Allozyme analyses for $\mathrm{T}$. erectum}

For T. erectum, all seven loci assayed were polymorphic, and the mean number of alleles per locus was 2.57 (Table 1). Expected heterozygosity was slightly greater than observed heterozygosity in five out of seven cases, indicating a slight tendency towards heterozygote deficit at some loci. However, averaged across loci, mean expected heterozygosity $(0.326)$ was nearly equal to mean observed heterozygosity $(0.324)$ (Table 1$)$.

Fixation indices. The overall $F_{\mathrm{ST}}$ value was positive and significantly different from zero $(0.043 \pm 0.016)$, indicating moderate differentiation over the small geographical area studied (Table 2a). The largest values of $F_{\mathrm{ST}}$ were found at the $M D H-2$ and $6 P G D-1$ loci. In five out

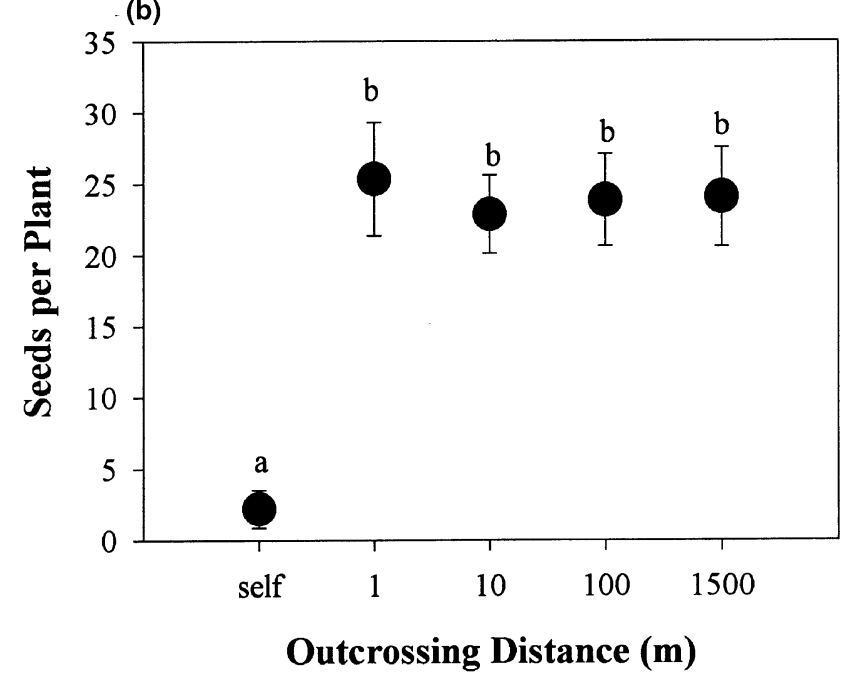

Fig. 2 Trillium grandiflorum: number of seeds per fruit (mean $\pm 1 \mathrm{SE}$ ) from crosses with donors at (a) four distance classes in 1998 and (b) five distance classes in 1999. Symbols as in Fig. 1.

of seven cases, $F_{\text {IS }}$ was positive, which could indicate bi-parental inbreeding and/or genetic substructuring. However, over all loci, $F_{\text {IS }}$ was slightly negative, although not significantly different from zero, indicating, overall, no substantial inbreeding (Table 2a). The total fixation index, $F_{\mathrm{IT}}$, was positive but did not differ significantly from zero (Table $2 a)$.

Spatial autocorrelation analysis. Values of Moran's I were first compared over short distance classes $(0 \mathrm{~m}-$ $150 \mathrm{~m}$; within-population comparisons) and long distance classes $(1360 \mathrm{~m}-1620 \mathrm{~m}$; between-population comparisons). Three loci ( $6 P G D-2, I D H, S K D H)$ exhibited higher values of Moran's $I$ over short distance classes than over long distance classes (Fig. 3a), indicating that pairs of $T$. erectum within the same population were more likely to be genetically similar than pairs of $T$. erectum in

(C) The Genetics Society of Great Britain, Heredity, 87, 178-189. 
different populations for these loci. For all other loci, values of Moran's $I$ were either similar between short and long distance classes ( $M D H-1, M D H-2, P G M)$, or longer distance classes exhibited higher values of Moran's $I$ (6PGD-1) (Fig. 3a). In general, however, for individual loci and averaged across loci, values of Moran's I fluctuated around zero with occasional significant negat-

Table 1 Indices of genetic variation for Trillium erectum

\begin{tabular}{|c|c|c|c|c|}
\hline Locus & $A$ & $\begin{array}{c}\text { Allele } \\
\text { frequencies }\end{array}$ & $H_{\mathrm{o}}$ & $H_{\mathrm{e}}$ \\
\hline$M D H-1$ & 2 & $\begin{array}{l}0.243 \\
0.757\end{array}$ & 0.324 & 0.371 \\
\hline$M D H-2$ & 3 & $\begin{array}{l}0.885 \\
0.101 \\
0.014\end{array}$ & 0.149 & 0.207 \\
\hline $6 P G D-1$ & 3 & $\begin{array}{l}0.196 \\
0.534 \\
0.270\end{array}$ & 0.784 & 0.608 \\
\hline $6 P G D-2$ & 2 & $\begin{array}{l}0.027 \\
0.973\end{array}$ & 0.054 & 0.053 \\
\hline$I D H$ & 2 & $\begin{array}{l}0.189 \\
0.811\end{array}$ & 0.297 & 0.309 \\
\hline$S K D H$ & 3 & $\begin{array}{l}0.858 \\
0.135 \\
0.007\end{array}$ & 0.216 & 0.247 \\
\hline$P G M$ & 3 & $\begin{array}{l}0.068 \\
0.655 \\
0.277\end{array}$ & 0.446 & 0.492 \\
\hline Mean $( \pm$ SD) & $\begin{array}{l}2.57 \\
(0.53)\end{array}$ & - & $\begin{array}{c}0.324 \\
(0.239)\end{array}$ & $\begin{array}{c}0.326 \\
(0.185)\end{array}$ \\
\hline
\end{tabular}

$A$, number of alleles; $H_{\mathrm{o}}$, observed heterozygosity; $H_{\mathrm{e}}$, expected heterozygosity. Values in parentheses are standard deviations. ive and positive values, with a weak trend for more negative values over longer distance intervals (i.e. $100 \mathrm{~m}$ and above; Fig. 3a). Taken together, these results demonstrate only weak isolation by distance.

Mantel test. The Mantel test, which examined the association between the $T$. erectum genetic and physical distance matrices, corroborated the results demonstrated in the spatial autocorrelation analyses above. The genetic distance matrix was not significantly correlated with the physical distance matrix (Mantel test: $Z=0.112, P=0.980)$, indicating that genetic distance did not significantly change with increasing physical distance for $T$. erectum.

\section{Allozyme analyses for $\mathrm{T}$. grandiflorum}

For $T$. grandiflorum, six of eight loci were polymorphic, and the mean number of alleles per locus was 2.00 (Table 3). Observed heterozygosity was slightly greater than expected heterozygosity in five out of six cases, indicating a slight heterozygote excess. However, mean observed heterozygosity (0.333) did not deviate significantly from mean expected heterozygosity (0.278) $(P>0.05$; Table 3$)$.

Fixation indices. The overall $F_{\mathrm{ST}}$ value was positive and significantly different from zero $(0.044 \pm 0.027)$, indicating moderate spatial genetic differentiation over the small geographical area studied (Table $2 b$ ). The largest values of $F_{\mathrm{ST}}$ were found at the $6 P G D-1$ and $I D H$ loci. $F_{\text {IS }}$ was negative at five of six loci, indicating heterozygote excess within individual samples, and the
Table $2 F$-statistics (means with variances in parentheses) for

(a) Trillium erectum and

(b) $T$. grandiflorum calculated by methods from Weir \& Cockerham (1984). $F_{\text {ST }}$ calculated by the methods of Weir \& Cockerham (1984) can give negative values

\begin{tabular}{lccr}
\hline Locus & $F_{\mathrm{IS}}$ & $F_{\mathrm{ST}}$ & \multicolumn{1}{c}{$F_{\mathrm{IT}}$} \\
\hline (a) $T$. erectum & & & \\
$M D H-1$ & $0.122(0.155)$ & $0.001(0.037)$ & $0.120(0.140)$ \\
$M D H-2$ & $0.339(0.306)$ & $0.078(0.054)$ & $0.403(0.319)$ \\
$6 P G D-1$ & $-0.375(0.135)$ & $0.079(0.069)$ & $-0.271(0.090)$ \\
$6 P G D-2$ & $-0.022(0.015)$ & $-0.005(0.021)$ & $-0.027(0.017)$ \\
IDH & $0.006(0.156)$ & $0.044(0.040)$ & $0.043(0.110)$ \\
SKDH & $0.125(0.105)$ & $0.014(0.044)$ & $0.135(0.089)$ \\
$P G M$ & $0.091(0.173)$ & $0.023(0.025)$ & $0.113(0.181)$ \\
Overall & $-0.038(0.123)$ & $0.043 *(0.016)$ & $0.005(0.104)$ \\
(b) $T$. grandiflorum & & & \\
$M D H-3$ & $-0.140(0.005)$ & $-0.018(0.001)$ & $-0.160(0.005)$ \\
$6 P G D-1$ & $0.050(0.155)$ & $0.109(0.048)$ & $0.151(0.123)$ \\
$6 P G D-2$ & $-0.107(0.030)$ & $0.025(0.025)$ & $-0.079(0.037)$ \\
$I D H$ & $-0.064(0.028)$ & $0.081(0.062)$ & $0.024(0.094)$ \\
$S K D H$ & $-0.683(0.063)$ & $0.005(0.009)$ & $-0.676(0.065)$ \\
$P G M$ & $-0.369(0.089)$ & $0.019(0.020)$ & $-0.345(0.062)$ \\
Overall & $-0.265^{*}(0.153)$ & $0.044^{*}(0.027)$ & $-0.206^{*}(0.176)$ \\
\hline$* P<0.05$. & & &
\end{tabular}

(C) The Genetics Society of Great Britain, Heredity, 87, 178-189. 
(a)

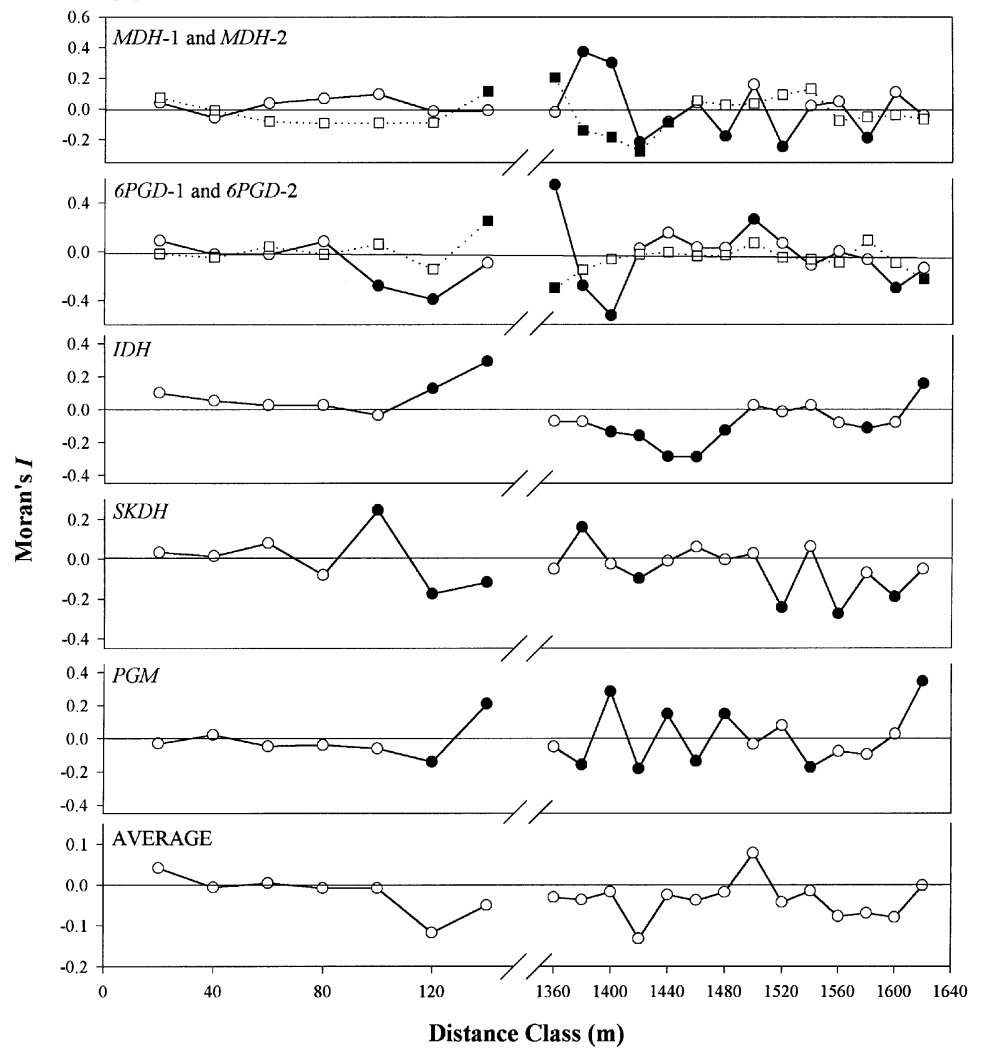

(b)

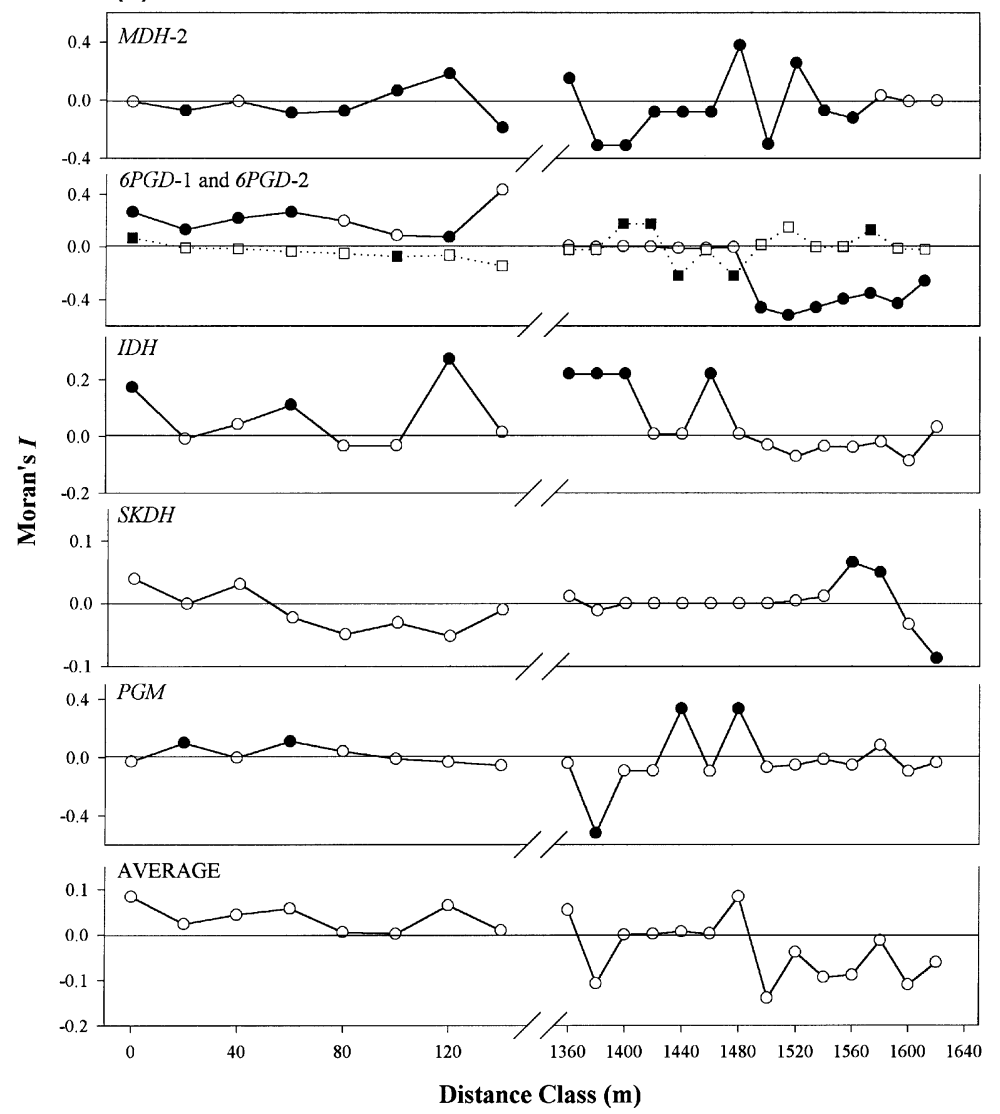

Fig. 3 Spatial autocorrelation correlograms for Moran's $I$ for the most common allele at (a) seven loci for Trillium erectum and (b) six loci for T. grandiflorum. In correlograms with two loci, circles depict values of Moran's $I$ at the first locus $(M D H-1,6 P G D-1)$ and squares depict values of Moran's $I$ at the second locus ( $M D H-2,6 P G D-2)$. Filled symbols indicate significant values of Moran's $I$ at $P<0.05$ after sequential Bonferroni corrections. 
Table 3 Indices of genetic variation for Trillium grandiflorum. Legend as in Table 1

\begin{tabular}{lccll}
\hline Locus & $A$ & $\begin{array}{c}\text { Allele } \\
\text { frequencies }\end{array}$ & \multicolumn{1}{c}{$H_{\mathrm{o}}$} & \multicolumn{1}{c}{$H_{\mathrm{e}}$} \\
\hline$M D H-1$ & 1 & 1.0 & 0 & 0 \\
$M D H-2$ & 1 & 1.0 & 0 & 0 \\
$M D H-3$ & 2 & 0.862 & 0.277 & 0.240 \\
& & 0.138 & & \\
$6 P G D-1$ & 3 & 0.505 & 0.489 & 0.566 \\
& & 0.420 & & \\
$6 P G D-2$ & 2 & 0.075 & & \\
& & 0.074 & 0.149 & 0.139 \\
$I D H$ & 3 & 0.926 & & \\
& & 0.144 & 0.298 & 0.292 \\
& & 0.026 & & \\
& 2 & 0.495 & 0.804 & 0.503 \\
& & 0.505 & & \\
& 2 & 0.403 & 0.649 & 0.482 \\
Mean $( \pm \mathrm{SD})$ & 2.00 & 0.597 & & \\
& $(0.76)$ & & 0.333 & 0.278 \\
& & & $(0.294)$ & $(0.224)$ \\
\hline
\end{tabular}

overall value of $F_{\text {IS }}$ was significantly less than zero, indicating dissortative mating (Table $2 \mathrm{~b}$ ). The total fixation index, $F_{\mathrm{IT}}$, was negative at four of six loci with an overall value of -0.206 , which was significantly less than zero (Table $2 b$ ), again indicating overall heterozygote excess.

Spatial autocorrelation analysis. Higher values of Moran's $I$ were detected over shorter distance classes ( $0 \mathrm{~m}-150 \mathrm{~m}$; within-population comparisons) than over longer distance classes (1340 m-1620 m; between-population comparisons) for all loci except $6 P G D-2$ and $S K D H$ (Fig. 3b), indicating that pairs of T. grandiflorum growing in the same population were more likely to be genetically similar than pairs of $T$. grandiflorum growing in different populations. Values of Moran's $I$ for individual loci and averaged across loci fluctuated around zero with occasional significant positive and negative values with a weak trend for more negative values over longer distance intervals, especially between populations sampled (Fig. 3b).

Mantel test. The relationship between the genetic and physical distance matrices showed significant association (Mantel test: $Z=0.200, P=0.001$ ). Therefore, genetic distance increased with geographical distance.

\section{Discussion}

Neither $T$. erectum nor $T$. grandiflorum exhibited an optimal outcrossing distance for fruit or seed production over a spatial scale ranging from $1 \mathrm{~m}$ to $1500 \mathrm{~m}$. Selfpollinated plants did produce significantly fewer fruits and seeds than outcrossed plants. However, there were no significant differences among outcrossing treatments in fruit or seed production both for crosses between plants growing in the same population and between plants growing in different populations. Even at the longest distance class, $1500 \mathrm{~m}$, no evidence was found of either outbreeding depression or heterosis. Lack of bi-parental inbreeding and outbreeding depression and heterosis over various spatial scales has been found in another member of the Liliaceae, Amianthium muscaetoxicum (Redmond et al., 1989).

Optimal outcrossing theory assumes a negative association between the genetic similarity and physical distance of mates (Price \& Waser, 1979; Waser \& Price, 1983). Since neither $T$. erectum nor $T$. grandiflorum exhibited an optimal outcrossing distance, it was predicted that populations of the two Trillium species would not demonstrate strong isolation by distance. The allozyme results did not fully support the patterns revealed in the outcrossing treatments. The significant positive $F_{\mathrm{ST}}$ values demonstrated by $T$. erectum and $T$. grandiflorum populations $(0.043$ and 0.044 , respectively) indicate substantial spatial genetic structure over the small geographical area sampled. Spatial autocorrelation analyses did not detect conclusive evidence for genetic isolation by distance for T. erectum, as predicted from the outcrossing results. However, T. grandiflorum did exhibit strong isolation by distance, as indicated by spatial autocorrelation analyses and a Mantel test. This result is surprising considering the mating system of each species. Trillium grandiflorum is predominantly an outcrosser and would be expected to exhibit less isolation by distance due to long-distance pollination events compared to $T$. erectum, which has a mixed mating system (Broyles et al., 1997; Kalisz et al., 1999) and dipteran pollinators which exhibit low flower constancy and little pollen carryover (i.e. Herrera, 1987; Olesen \& Warncke, 1989; see Proctor et al., 1996 for a review). Yet, T. grandiflorum may exhibit stronger isolation by distance than $T$. erectum because it is capable of autogamy when pollinators are scarce; whereas, T. erectum requires insect vectors for selfed as well as outcrossed pollination (Fukuda \& Grant, 1980; Broyles et al., 1997; but see Kalisz et al., 1999). In general, the levels of allozyme variation in T. erectum and $T$. grandiflorum from Vermont populations are similar to those reported from central New York (Broyles et al., 1997).

Selection (e.g. Waser, 1987; Campbell \& Dooley, 1992), stochastic effects (e.g. Epperson \& Clegg, 1986), and limited gene flow (e.g. Williams, 1994) have all been proposed as factors influencing population genetic 
structure and isolation by distance. The levels of spatial genetic structure and isolation by distance exhibited by $T$. erectum and $T$. grandiflorum populations may be attributed to a number of variable factors, including active seed dispersal by ants, rare long-distance geneflow events, post-pollination and post-fertilization selection, and/or the severity of inbreeding depression. These factors are not mutually exclusive and are discussed below.

Many studies have found that seed dispersal is a primary factor influencing variation in gene flow and population structure (e.g. Hamrick \& Godt, 1996; Kalisz et al., 1999). Although the average seed dispersal distance of $T$. erectum seeds is unknown, ant-mediated seed dispersal of $T$. grandiflorum seeds ranges from $0.02 \mathrm{~m}$ to $10 \mathrm{~m}$, with an average dispersal distance of approximately $1.5 \mathrm{~m}$ (Kalisz et al., 1999). In T. grandiflorum, seed dispersal reduces the probability of siblings being neighbours (Kalisz et al., 1999). Thus, seed dispersal may play a central role in genetically homogenizing $T$. erectum and $T$. grandiflorum populations over short distance intervals. In other studies demonstrating optimal outcrossing distances, focal plants typically had limited, leptokurtic pollen movement and no active seed dispersal. More work is needed to address the importance of active seed dispersal in influencing the occurrence of optimal outcrossing distances.

Ant-mediated seed dispersal may counteract spatial patterns of relatedness within populations, but it is unlikely to affect gene flow between populations and thus does not explain the spatial patterns of relatedness exhibited by T. erectum (Kalisz et al., 1999). However, rare long-distance gene-flow events via pollination or seed dispersal could counteract genetic subdivision within T. erectum populations and isolation by distance among T. erectum populations (e.g. Campbell \& Dooley, 1992). Although the pollinators of T. erectum, primarily dipterans, are predicted to have low flower constancy and little pollen carryover (Herrera, 1987; Olesen \& Warncke, 1989), rare long-distance flights could serve to limit isolation by distance. Rare, long-distance pollinator flights can increase neighbourhood size both within continuous populations as well as among distinct populations in several plant species (e.g. Campbell \& Dooley, 1992). Long-distance seed-dispersal events may also offset localized gene flow. These long-distance seeddispersal events, although probably not mediated by ants, may be mediated by other biotic mechanisms in Trillium, such as wasps (Jules, 1996), or by abiotic mechanisms, such as water.

Further, post-pollination and post-fertilization selection may modify patterns established by mating and gene flow. For example, in mixed pollen loads on the same stigma, pollen from longer distances might gain an advantage due to differential success of pollen-tube growth (e.g. Waser \& Price, 1991, 1993). Moreover, patterns established by pollen flow may be modified by selection against certain progeny during seed maturation, seed dispersal, germination, establishment, and the prolonged juvenile stage. Furthermore, Trillium are extremely long-lived, and individual plants can survive for up to 40 years. Thus, proximate plants probably have had a long time for most members of the same kinship to die out. Therefore, plant demography may be an important link to understanding patterns established by mating and gene flow. Work using a genetic demography approach will elucidate the importance of each of these mechanisms to spatial genetic structure in $T$. erectum and $T$. grandiflorum populations.

Moreover, the severity of inbreeding depression may also influence spatial genetic patterns in $T$. erectum and $T$. grandiflorum populations. Theory predicts that if selfpollinated individuals experience greater than a $50 \%$ reduction in seed production, then breeding systems should evolve to be predominantly outcrossing (Lloyd, 1979; Lande \& Schemske, 1985). Negative selection against inbreeding should serve to genetically homogenize populations. For T. erectum and T. grandiflorum, self-pollinated plants experienced a $71 \%$ and $89 \%$ reduction, respectively, in seed production for selfed vs. outcrossed progeny. This reduction is well above the theoretical threshold of $50 \%$ reduction in reproductive success needed to promote outcrossing breeding systems. Therefore, the severity of inbreeding depression may serve to increase outcrossing and decrease genetic structure.

One caveat to the interpretation of the outcrossing results presented here is that the present data only show that an optimal outcrossing distance does not exist for fruit or seed production over a spatial scale of $1 \mathrm{~m}$ to $1500 \mathrm{~m}$. However, an optimal outcrossing distance may still exist for one or both species for numerous reasons (Waser, 1993), three of which are described here.

First, outcrossing distance may affect not only the number of seeds produced but also the germination, survival, and subsequent fitness of those offspring (e.g. Waser \& Price, 1985, 1989; Lynch, 1991), and the definitive importance of inbreeding and outbreeding depression may only become apparent in $F_{2}$ and subsequent generations (Lynch, 1991). For T. erectum and $T$. grandiflorum, selfed progeny experience strong negative selection pressures and high mortality during seed dispersal, germination, establishment, and the prolonged juvenile stage (Davis, 1981; Kawano et al., 1986; Hanzawa \& Kalisz, 1993; Kalisz et al., 1999). Therefore, to assess the ultimate importance of optimal outcrossing distance for $T$. erectum and $T$. grandiflorum, long-term studies are needed to measure offspring 
survival and fecundity from crosses at various spatial distances (Lynch, 1991). Since Trillium species are longlived perennials, this work would involve numerous decades of study.

Second, spatial and temporal variation in gene flow and selection regimes may influence the probability of detecting an optimal outcrossing distance in a given year. Spatial genetic structure in a plant population depends on past gene-flow events via seeds and pollen and on selection patterns, all of which may vary spatially and temporally. Since $T$. erectum and $T$. grandiflorum are long-lived species and individuals switch from reproductive to non-reproductive stages numerous times during their life-times and there is new recruitment of individuals into reproductive stages each year, reproductive individuals separated at a distance class of $100 \mathrm{~m}$ in a given year may be very different genetically from individuals separated by that same distance class in the next year. Indeed, the effects of spatial and temporal variation on the intensity of inbreeding depression, outbreeding depression, and heterosis are well documented (see Waser et al., 2000 for a review). Rather than using discrete distances classes, future studies in optimal outcrossing may need to treat distance class as a continuous variable to incorporate variation in both shorter and longer distance ranges to detect optimal outcrossing in populations of spatially and temporally variable species.

Finally, the ability to detect an optimal outcrossing distance may be compromised by low statistical power. In Delphinium nelsonii, a significant trend towards an intermediate optimal outcrossing distance was only detected after 11 years of experimental pollinations, many individual years of which often showed no significant effect (Waser, 1993). In the two years of experimental pollinations performed here, 10 plants per outcrossing treatment were used in 1998 and 18 and 14 plants for T. erectum and T. grandiflorum, respectively, in 1999. Statistical power increases with experimental repetition; therefore, larger sample sizes over multiple years may be needed to detect a significant result. Indeed, a power analysis indicates that, in a given year, at least $112 T$. erectum and $T$. grandiflorum per treatment would be needed to find a significant difference among outcrossing treatments in seed production at $\alpha=0.05$. However, increased sample sizes and statistical significance do not equate to biological relevance. Ultimately, the biological importance of small or moderate effects of outcrossing on fecundity may be most applicable if detected consistently over multiple years (Waser, 1993).

In summary, understanding the phenomenon of optimal outcrossing and its relationship to plant reproductive biology and plant taxonomy is still in its infancy.
In the work presented here, neither $T$. erectum nor $T$. grandiflorum exhibited an optimal outcrossing distance for fruit or seed production over a spatial scale of $1 \mathrm{~m}$ to $1500 \mathrm{~m}$. Populations of $T$. erectum and $T$. grandiflorum exhibited moderate spatial differentiation, and $T$. grandiflorum exhibited stronger isolation by distance than $T$. erectum. Patterns of allozyme variation in $T$. erectum and $T$. grandiflorum may be attributed to a number of factors, including active seed dispersal by ants, rare long-distance gene-flow events, post-pollination and post-fertilization selection, and/or the severity of inbreeding depression. Knowledge of inbreeding and outbreeding depression has important evolutionary implications for plant mating systems, pollen- and seed-dispersal strategies, and speciation as well as conservation implications for rare and endangered plants. However, truly understanding the biological relevance of optimal outcrossing in plants requires knowledge of its effects in $\mathrm{F}_{2}$ and subsequent generations (Waser \& Price, 1989; Lynch, 1991; Waser, 1993). The next step in this system is to conduct long-term field and allozyme studies at both shorter and longer spatial scales to determine the ultimate importance of outcrossing distance and spatial genetic structure to offspring success in the long-lived spring ephemerals $T$. erectum and $T$. grandiflorum.

\section{Acknowledgements}

I thank T. Irwin and B. Taylor for help in the field, and S. Broyles for his insight into electrophoresis in Trillium. Comments from A. Brody, S. Griffin, M. Price, B. Taylor, N. Waser, and two anonymous reviewers greatly improved the manuscript. This work was supported by research grants from the Central Vermont Audubon Society and the Lake Champlain Research Consortium and a training grant to the University of Vermont from the National Science Foundation (U.S.A.).

\section{References}

BOURNIVAL, B. L. AND KORBAN, S. S. 1987. Electrophoretic analysis of genetic variability in the apple. Scientia Hort., 31, 233-243.

BROYLES, S. B., SHERMAN-BROYLES, S. L. AND ROGATI, P. 1997. Evidence of outcrossing in Trillium erectum and Trillium grandiflorum (Liliaceae). Heredity, 88, 325-329.

CAMPBEll, D. R. AND DOOLEY, J. L. 1992. The spatial scale of genetic differentiation in a hummingbird-pollinated plant: comparison with models of isolation by distance. Am. Nat., 139, 735-748.

ClAyton, J. W. AND TRETiAK, D. N. 1972. Amine-citrate buffers for $\mathrm{pH}$ control in starch gel electrophoresis. J. Fish Res. Board Can., 29, 1169-1172. 
COCKERHAM, C. C. AND WEIR, B. S. 1977. Quadratic analyses of reciprocal crosses. Biometrics, 33, 187-203.

CONSTANTINE, C. C., HOBBS, R. P. AND LYMBERY, A. J. 1994. FORTRAN programs for analyzing population structure from multilocus genotype data. J. Hered., 85, 336-337.

DAVIS, M. A. 1981. The effect of pollinators, predators, and energy constraints on the floral ecology and evolution of Trillium erectum. Oecologia, 48, 400-406.

EPPERSON, B. K. AND CLEGG, M. T. 1986. Spatial-autocorrelation analysis of flower color polymorphisms within substructured populations of morning glory (Ipomoea purpurea). Am. Nat., 128, 840-858.

FISCHER, M. AND MATTHIES, D. 1997. Mating structure and inbreeding and outbreeding depression in the rare plant Gentianella germanica (Gentianaceae). Am. J. Bot., 84, 1685-1692.

FUKUDA, I. AND GRANT, W. F. 1980. Chromosome variation and evolution in Trillium grandiflorum. Can. J. Genet. Cytol., 22, 81-91.

GOUDET, J. 1995. FSTAT (Version 1.2): a computer program to calculate $F$-statistics. J. Hered., 86, 485-486.

HAMRICK, J. L. AND GODT, M. J. W. 1996. Effects of life history traits on genetic diversity in plant species. Phil. Trans. R. Soc. B, 351, 1291-1298.

HANZAWA, F. M. AND KALISZ, s. 1993. The relationship between age, size, and reproduction in Trillium grandiflorum (Liliaceae). Am. J. Bot., 80, 405-410.

HERRERA, C. M. 1987. Components of pollinator 'quality': a comparative analysis of a diverse insect assemblage. Oikos, 50, 79-90.

IRWIN, R. E. 2000. Morphological variation and female reproductive success in two sympatric Trillium species: evidence for phenotypic selection in Trillium erectum and Trillium grandiflorum (Liliaceae). Am. J. Bot., 87, 205-214.

JULES, E. S. 1996. Yellow jackets (Vespula vulgaris) as a second seed disperser for the myrmecochorous plant, Trillium ovatum. Am. Midl. Nat., 135, 367-369.

KAlisz, S., HANZAWA, F. M., TONSOR, S. J., THIEDE, D. A. ET $A L$. 1999. Ant-mediated seed dispersal alters pattern of relatedness in a population of Trillium grandiflorum. Ecology, 80, 2620-2634.

KAWANO, S., OHARA, M. AND UTECH, F. H. 1986. Life history studies on the genus Trillium (Liliaceae). II. Reproductive biology and survivorship of four eastern North American species. Plant Spec. Biol., 1, 47-58.

KIMURA, M. AND WEISS, G. H. 1964. The stepping-stone model of population structure and the decrease of genetic correlation with distance. Genetics, 49, 561-576.

LANDE, R. AND SCHEMSKE, D. W. 1985. The evolution of selffertilization and inbreeding depression in plants. I. Genetic models. Evolution, 39, 24-40.

LEVIN, D. A. AND KERSTER, H. W. 1974. Gene flow in seed plants. Evol. Biol., 7, 139-220.

LLOYD, D. G. 1979. Some reproductive factors affecting the selection of self-fertilization in plants. Am. Nat., 113, $67-79$.

LYNCH, M. 1991. The genetic interpretation of inbreeding depression and outbreeding depression. Evolution, 45, 622-629.
MANTEL, N. A. 1967. The detection of disease clustering and a generalized regression approach. Cancer Res., 27, 209-220.

MÜLlER, H. 1883. The Fertilization of Flowers. Macmillan, London.

OLESEN, J. M. AND WARNCKE, E. 1989. Temporal changes in pollen flow and neighborhood structure in a population of Saxifraga hirculus L. Oecologia, 72, 205-211.

OOSTERMEIJER, J. G. B., ALTENBURG, R. G. M. AND DEN NIJS, H.C. M. 1995. Effects of outcrossing distance and selfing on fitness components in the rare Gentiana pneumonanthe (Gentianaceae). Acta Bot. Neerl., 44, 257-268.

PRICE, M. V. AND WASER, N. M. 1979. Pollen dispersal and optimal outcrossing in Delphinium nelsonii. Nature, 277, 294-297.

PROCTOR, M., YEO, P. AND LACK, A. 1996. The Natural History of Pollination. Timber Press, Portland, OR.

REDMOND, A. M., ROBBINS, L. E. AND TRAVIS, J. 1989. The effects of pollination distance on seed production in three populations of Amianthium muscaetoxicum (Liliaceae). Oecologia, 79, 260-264.

ROGERS, J. S. 1972. Measures of genetic similarity and genetic distance. Studies in Genetics VII. University of Texas Publication, 7213, 145-153.

ROHLF, F. J. AND SCHNELL, G. D. 1971. An investigation of the isolation-by-distance model. Am. Nat., 105, 295-324.

SAWADA, M. 1999. ROOKCASE: an EXCEL 97/2000 visual basic (VB) add-in for exploring global and local spatial autocorrelation. Bull. Ecol. Soc. Am., 80, 231-234.

SCHEMSKE, D. W. AND PAULTER, L. P. 1984. The effects of pollen composition on fitness components in a neotropical herb. Oecologia, 62, 31-36.

SHIELDS, W. M. 1982. Philopatry, Inbreeding, and the Evolution of Sex. State University of New York Press, Albany, NY.

SOBREVILA, C. 1988. Effects of distance between pollen donor and pollen recipient on fitness components in Espeletia schultzii. Am. J. Bot., 75, 701-724.

SOKAL, R. R. AND ODEN, N. L. 1978. Spatial autocorrelation in biology. I. Methodology. Biol. J. Linn. Soc., 10, 199-228.

SOKAL, R. R. AND ROHLF, J. F. 1995. Biometry, 3rd edn. W. H. Freeman, New York.

SOKAL, R. R. AND WARTENBERG, D. E. 1983. A test of spatial autocorrelation analysis using an isolation-by-distance model. Genetics, 105, 219-237.

TRAME, A.-M., CODDington, A. J. AND PAige, K. N. 1995. Field and genetic studies testing optimal outcrossing in Agave schottii, a long-lived clonal plant. Oecologia, 104, 93-100.

VRIJENHOEK, R. C. AND LERMAN, S. 1982. Heterozygosity and developmental stability under sexual and asexual breeding systems. Evolution, 36, 768-776.

WASER, N. M. 1987. Spatial genetic heterogeneity in a population of the montane perennial plant Delphinium nelsonii. Heredity, 58, 249-256.

WASER, N. M. 1993. Population structure, optimal outbreeding, and assortative mating in angiosperms. In: Thornhill, N. W. (ed.) The Natural History of Inbreeding and Outbreeding, pp. 173-199. University of Chicago Press, Chicago, IL.

WASER, N. M. AND PRICE, M. V. 1983. Optimal and actual outcrossing in plants, and the nature of plant-pollinator interaction. In: Jones, C. E. and Little, R. J. (eds) Handbook 
of Experimental Pollination Biology, pp. 341-359. Van Nostrand Reinhold Co, New York.

WASER, N. M. AND PRICE, M. V. 1985. Reciprocal transplant experiments with Delphinium nelsonii (Ranunculaceae): evidence for local adaptation. Am. J. Bot., 72, 1726-1732.

WASER, N. M. AND PRICE, M. V. 1989. Optimal outcrossing in Ipomopsis aggregata: seed set and offspring fitness. Evolution, 43, 1097-1109.

WASER, N. M. AND PRICE, M. V. 1991. Outcrossing distance effects in Delphinium nelsonii: pollen loads, pollen tubes, and seed set. Ecology, 72, 171-179.

WASER, N. M. AND PRICE, M. V. 1993. Crossing distance effects on prezygotic performance in plants: an argument for female choice. Oikos, 68, 303-308.
WASER, N. M., PRICE, M. V. AND SHAw, R. G. 2000. Outbreeding depression varies among cohorts of Ipomopsis aggregata planted in nature. Evolution, 54, 485-491.

WEIR, B. S. AND COCKERHAM, C. C. 1984 . Estimating $F$-statistics for the analysis of population structure. Evolution, 38, 1358-1370.

WILliAMS, C. F. 1994. Genetic consequences of seed dispersal in three sympatric forest herbs: II. Microspatial genetic structure within populations. Evolution, 48, 1959-1972.

WRIGHT, S. 1943. Isolation by distance. Genetics, 28, 114-138. Wright, s. 1951. The genetical structure of populations. Ann. Eugen., 15, 323-354. 